\title{
PENENTUAN HIPOSENTER DAN EPISENTER GEMPA VOLKANIK GUNUNG MERAPI DENGAN HIPO9
}

\author{
Syahrial Ayub ${ }^{1)}$, Joni Rokhmat ${ }^{1}$, Ahmad Harjono'), Wahyudi' ${ }^{1)}$ \\ 1)Program Studi Pendidikan Fisika, FPMIPA Universitas Mataram, Mataram, Indonesia \\ Corresponding author : Syahrial Ayub \\ E-mail : syahrial_ayub@unram.ac.id
}

\section{Diterima 27 Maret 2020, Disetujui 7 April 2020}

\begin{abstract}
ABSTRAK
Telah dilakukan penelitian terhadap gempa volkanik gunung Merapi. Penelitian ini bertujuan menentukan hiposenter dan episenter gempa volkanik gunung Merapi dengan HIPO9. Analisis dilakukan dalam dua kawasan, yaitu kawasan waktu dan kawasan frekuensi. Dalam kawasan waktu ditentukan waktu tiba gempa volkanik. Dalam kawasan frekuensi diperoleh informasi tentang frekuensi sumber dan lebar pita frekuensi yang akan diloloskan. Hasil analisis mendapatkan frekuensi sumber 6 $\mathrm{Hz}$ dan lebar pita frekuensi $0,1 \mathrm{~Hz}$. Hasil pengeplotan dengan HIPO9, episenter gempa volkanik cenderung mengumpul di sekitar puncak gunung merapi, dengan hiposenter gempa volkanik terdistribusi pada kedalaman $1200 \mathrm{~m}$ sampai $1300 \mathrm{~m}$.
\end{abstract}

Kata kunci : hiposenter; episenter; gunung Merapi; HIPO9; gempa volkanik.

\begin{abstract}
Volcanic earthquakes of mount Merapi have been investigated. The aim of the investigation to determine the hypocenter and epicenter of the volcanic earthquake of mount Merapi by HIPO9. The analysis was carried out in two domains, the time domain and the frequency domain. The analysis in the time domain was conducted by the arrival time of volcanic earthquake. The analysis in the frequency domain was done by observing spectrum to get information on frequency of source and frequency band width passed from polarization. The analysis lead to frequency of source $6 \mathrm{~Hz}$ and band width of $0,1 \mathrm{~Hz}$. The results of plotting with HIPO9, the epicenter of volcanic earthquakes tend to gather around the top of Mount Merapi, with the hypocenter of the volcanic earthquake distributed at a depth of $1200 \mathrm{~m}$ to $1300 \mathrm{~m}$.
\end{abstract}

Keywords: hypocenter; epicenter; mount Merapi; HIPO9; volcanic earthquake.

\section{PENDAHULUAN}

Gunung Merapi yang lerengnya menyebar di kabupaten Magelang, Boyolali, klaten, dan DIY, selain tercatat sebagai gunungapi teraktif di dunia, juga banyak menyimpan fenomena fisika yang sukar diamati seperti gejala gelombang bunyi (akustik) dan gejala deformasi (perubahan bentuk) (Kirbani, 1990). Selain kedua gejala ini, masih ada besaran fisika yang mungkin dapat dikorelasikan dengan dinamika internal gunungapi, antara lain perubahan medan geomagnetik, medan geolistrik dan suhu. Analisis data besaranbesaran ini sangat komplek karena dipengaruhi oleh banyak faktor luar. Berdasarkan hal ini, maka untuk pembuatan model, penentuan status dan prakiraan kegiatan volkanik sering digunakan gejala seismik dan deformasi tanpa mengabaikan gejala yang lain (Rahardja, 1984). Gunungapi merupakan obyek penelitian yang menarik bagi peneliti dan luar negeri. Kirbani (1996), dengan menggunakan seismik 3 komponen arah telah melakukan penelitian seismisitas di gunung Krakatau. Penelitian ini menyimpulkan bahwa bunyi dentuman letusan volkanik adalah akibat aliran gas dengan kecepatan supersonik (supersonic boom). Setiawan (1993), melakukan pengukuran seismik 3 komponen pada saat pembentukan kubah lava gunung Merapi. Penelitian ini berhasil menentukan parameter polarisasi (azimuth balik dan sudut datang). Wahyudi (1991), telah membuat deskripsi umum tentang jenis-jenis gempa volkanik. Penelitian ini menyimpulkan kemiripan spektrum suatu gejala seismik yang diterima 2 stasion dapat diasosiasikan dengan karakteristik sumber. Sukrisna (1997), dengan data seismik 3 komponen broadband pada 2 stasion dapat menentukan posisi sumber gempa volkanik dan kecepatan rerata gelombang seismik serta laju alir rerata fluida letusan di gunung Krakatau. Salah satu aspeknya yang lain adalah meneliti kondisi internal gunungapi melalui seismisitas kegempaan di gunung tersebut. Seismisitas 
yang dihasilkan oleh gempa volkanik dari proses internal dapat direkam oleh peralatan seismometer di permukaan. Hasil rekaman berupa data seismogram setelah diproses akan menjadi sesuatu yang membawa informasi (Bruestle,1985). Salah satu informasi penting adalah mengetahui posisi sumber gempa volkanik. Penentuan posisi sumber gempa volkanik ditentukan dengan cara mencari arah datangnya gelombang melalui pengukuran azimut balik dan sudut datang dengan metode analisis polarisasi gerak partikel (Scherbaum,1991). Tujuan penelitian ini adalah menentukan posisi hiposenter gempa volkanik gunung Merapi. Posisi gempa volkanik dapat memberikan informasi lanjut bagi kita tentang kondisi internal gunung Merapi. Syahrial A. (2019) gempa gunung Merapi menimbulkan gempabumi di daerah sekitar gunung Merapi tersebut. Gempabumi tidak dapat diprediksi sehingga ilmu tentang kegempaan harus selalu ditingkatkan.

\section{METODE PENELITIAN}

Menentukan posisi gempa volkanik dengan HIPO9 berdasarkan asumsi bahwa bumi mempunyai lapisan yang serba sama (homogen), sehingga kecepatan gelombang disemua titik dalam ruang pada semua arah adalah sama. Metode yang digunakan adalah penyelesaian persamaan jarak (antara sumber ke stasion). Stasion dalam hal ini dapat dianggap siesmometer karena gelombang pertama kali terekam oleh seismometer. Dasar teorinya adalah jarak antara dua titik $x$ dan y di dalam ruang 3 dimensi. Jika $x$ adalah suatu titik di dalam ruang 3 dimensi atau ditulis $\mathrm{x}=\left(\mathrm{x}_{1}, \mathrm{x}_{2}, \mathrm{x}_{3}\right)$ dan $\mathrm{y}=\left(\mathrm{y}_{1}, \mathrm{y}_{2}, \mathrm{y}_{3}\right)$, maka jarak antara $x$ dan $y$, adalah (Rahardja, 1984).

$$
d=\sqrt{\left(x_{1}-y_{1}\right)^{2}+\left(x_{2}-y_{2}\right)^{2}+\left(x_{a}-y_{1}\right)^{2}}
$$

Bila teori ini diterapkan pada sistem letak seismometer dengan hiposenter gempa volkanik gunung Merapi. Dikorelasikan dengan persamaan jarak (kecepatan dikalikan waktu), ilustrasinya dapat dilihat pada gambar berikut :

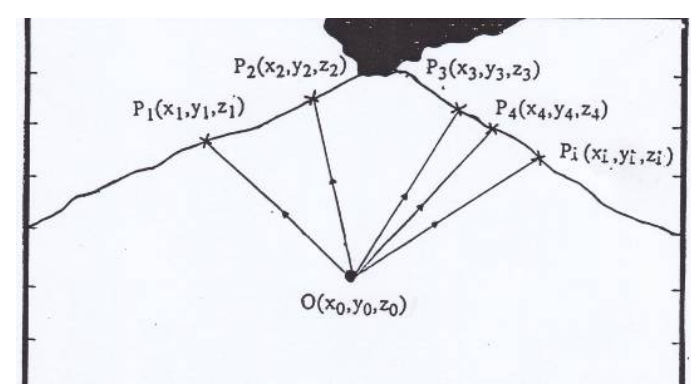

Gambar 1. Posisi Relatif Sumber Gempa Volkanik terhadap Perekam $\left(\mathrm{P}_{\mathrm{i}}\right)$
Andaikan $\mathrm{P}_{\mathrm{i}}\left(\mathrm{x}_{\mathrm{i}}, \mathrm{y}_{\mathrm{i}}, \mathrm{z}_{\mathrm{i}}\right)$ adalah tiap tiap seismometer, $t_{i}$ adalah waktu tiba gelombang pada tiap tiap seismometer $\mathrm{P}_{\mathrm{i}}, \mathrm{O}\left(\mathrm{x}_{\mathrm{o}}, \mathrm{y}_{\mathrm{o}}, \mathrm{z}_{\mathrm{o}}\right)$ adalah posisi hiposenter sedangan to adalah saat terjadinya gempa (origin time). Jarak antara hiposenter $\mathrm{O}$ ke seismometer $\mathrm{P}_{i}$ dapat dinyatakan sebagai produk dari waktu rambat gelombang (travel time) (T) dan kecepatan v. Waktu rambat $(T)$ ke tiap-tiap seismometer,

$$
T_{i}=t_{0}-t_{i}
$$

$$
\left(x_{0}-x_{i}\right)^{2}+\left(y_{0}-y_{i}\right)^{2}+\left(z_{0}-z_{i}\right)^{2}=v^{2}\left(t_{0}-t_{i}\right)^{2}
$$

terdapat 4 variabel yang harus ditentukan, yaitu $x_{0}, y_{o}, z_{o}$, dan $t_{o}$, sehingga diperlukan sekurang-kurangnya 4 persamaan untuk menyelesaikannya. Pada penelitian sebelumnya telah digunakan program HIPO untuk 4 stasion (Wahyudi, 1991). Pada penelitian ini, terdapat 9 alat perekam sinyal seismik yang tersebar pada 3 stasion (KLT, KEN dan SEL). Sesuai dengan itu, akan didapatkan 9 persamaan dari 9 seismometer dengan nilai kecepatan yang diasumsikan 2 $\mathrm{km} /$ det. Berikut adalah persamaan yang didapat,

$$
\begin{aligned}
& \left(x_{0}-x_{1}\right)^{2}+\left(y_{0}-y_{1}\right)^{2}+\left(z_{0}-z_{1}\right)^{2}-v^{2}\left(t_{0}-t_{1}\right)^{2}=0 \\
& \left(x_{0}-x_{2}\right)^{2}+\left(y_{0}-y_{2}\right)^{2}+\left(z_{0}-z_{2}\right)^{2}-v^{2}\left(t_{0}-t_{2}\right)^{2}=0 \\
& \left(x_{0}-x_{3}\right)^{2}+\left(y_{0}-y_{3}\right)^{2}+\left(z_{0}-z_{3}\right)^{2}-v^{2}\left(t_{0}-t_{3}\right)^{2}=0 \\
& \left(x_{0}-x_{4}\right)^{2}+\left(y_{0}-y_{4}\right)^{2}+\left(z_{0}-z_{4}\right)^{2}-v^{2}\left(t_{0}-t_{4}\right)^{2}=0 \\
& \left(x_{0}-x_{5}\right)^{2}+\left(y_{0}-y_{5}\right)^{2}+\left(z_{0}-z_{5}\right)^{2}-v^{2}\left(t_{0}-t_{5}\right)^{2}=0 \ldots \\
& \left(x_{0}-x_{6}\right)^{2}+\left(y_{0}-y_{6}\right)^{2}+\left(z_{0}-z_{6}\right)^{2}-v^{2}\left(t_{0}-t_{6}\right)^{2}=0 \\
& \left(x_{0}-x_{7}\right)^{2}+\left(y_{0}-y_{7}\right)^{2}+\left(z_{0}-z_{7}\right)^{2}-v^{2}\left(t_{0}-t_{7}\right)^{2}=0 \\
& \left(x_{0}-x_{8}\right)^{2}+\left(y_{0}-y_{8}\right)^{2}+\left(z_{0}-z_{8}\right)^{2}-v^{2}\left(t_{0}-t_{8}\right)^{2}=0 \\
& \left(x_{0}-x_{9}\right)^{2}+\left(y_{0}-y_{9}\right)^{2}+\left(z_{0}-z_{9}\right)^{2}-v^{2}\left(t_{0}-t_{9}\right)^{2}=0 .
\end{aligned}
$$

Berdasarkan persamaan 4.4 dengan mencari nilai yang memenuhi persamaan 4.4 dapat ditentukan $\mathrm{x}_{\mathrm{o}}, \mathrm{y}_{\mathrm{o}}, \mathrm{z}_{\mathrm{o}}$ dan to. Untuk keperluan ini dibuat program HIPO9 yang maksudnya menentukan episenter dan hiposenter gempa volkanik dengan menggunakan 9 seismometer yang tersebar di 3 stasion. Tiga stasion itu adalah Klatakan (KLT), Kendil (KEN) dan Selo (SEL). Berikut adalah diagram alir program HIPO9, 


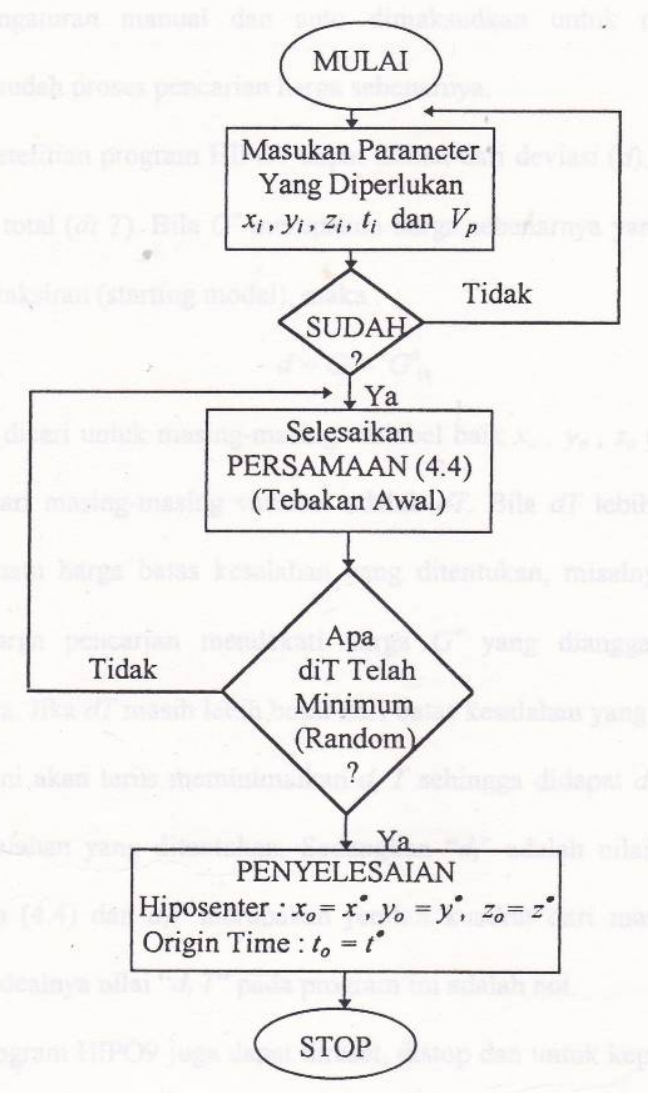

Gambar 2. Diagram Alir Program HIPO9

Prinsip program HIPO9 adalah mencari nilai terbaik (paling mendekati) dari persamaan 4.4 secara random dengan tebakan awal. Program HIPO9 dirancang untuk memeriksa 1600 titik pada tiap pencarian $x_{o}, y_{o}$, Zo dan to. Untuk lebih mengakuratkan yang didapat digunakan pemakaian interval dan range yang diatur secara manual dan auto. Pengaturan manual dan auto dimaksudkan untuk mempercepat dan mempermudah proses pencarian harga sebenarnya. Ketelitian HIPO9 dapat dilihat dari deviasi (d), deviasi total (dT) dan ditotal $\left(d_{i} T\right)$. Bila $G^{*}$ merupakan harga sebenarnya yang akan dicari dan $\mathrm{G}^{\circ}$ harga taksiran (starting model), maka,

$$
d=G^{*}-G^{\circ}
$$

Nilai "d" dicari untuk masing-masing variabel baik $x_{\circ}, y_{o}, z_{o}$ dan to dan jumlah kuadrat dari masing-masing variabel adalah $\mathrm{dT}$. Bila $\mathrm{dT}$ lebih kecil atau sama dengan suatu harga batas kesalahan yang ditentukan, $G^{*}$ yang dianggap sebagai harga sebenarnya. Jika dT masih lebih besar dari kesalahan yang ditentukan, maka program ini akan terus meminimalkan $d_{i} T$ sehingga didapat $d T$ yang kecil dari batas kesalahan yang ditentukan. $d_{i}$ adalah nilai ruas kanan dari persamaan 4.4 dan $\mathrm{d}_{\mathrm{i}} \mathrm{T}$ merupakan jumlah kuadrat dari masing masing $d_{i}$ sehinnga idealnya nilai $d_{i} T$ pada program ini adalah nol. HIPO9 juga dapat direset, distop dan untuk keperluan mengubah harga waktu tiba, posisi seismoter dan kecepatan gelombang disesuaikan dengan button yang tersedia. Kursor ditempatkan pada yang dikehendaki dan terus mengubahnya. Untuk lebih jelasnya tampilan program HIPO9 dapat dilihat pada gambar berikut ini,

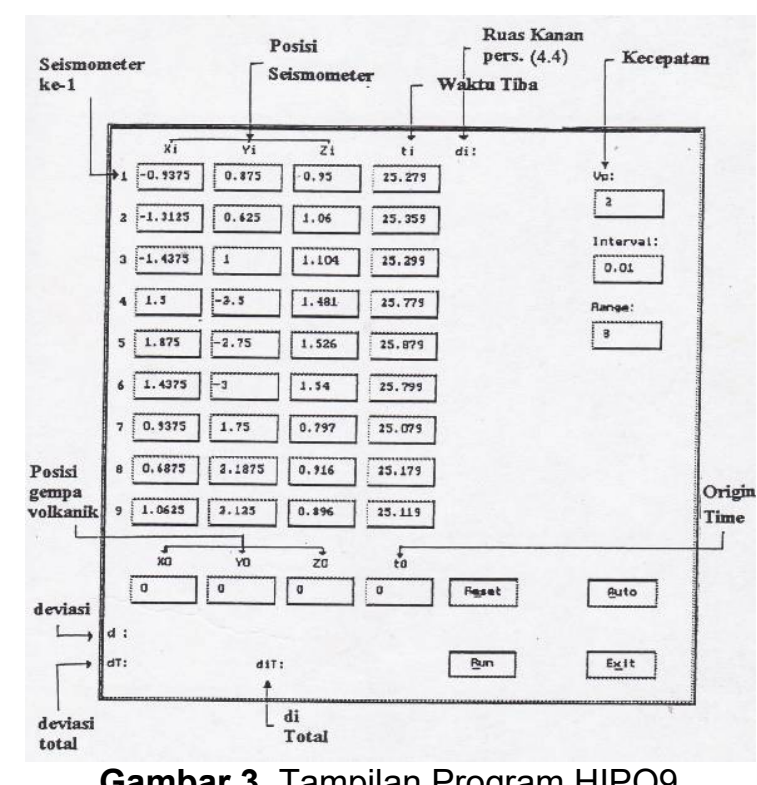

Gambar 3. Tampilan Program HIPO9

\section{HASIL DAN PEMBAHASAN}

Data rekaman gempa volkanik dari seismometer terdiri dari 3 komponen arah yaitu arah vertikal (Z), Utara-Selatan (N) dan TimurBarat $(E)$. Data ini berasal dari 3 stasion yaitu Klatakan (KLT). Kendil (KEN), Selo (SEL) yang tersebar di punggung gunung Merapi. Posisi dan data dari seismometer dapat dilihat pada gambar 4 dan gambar 5 berikut ini:

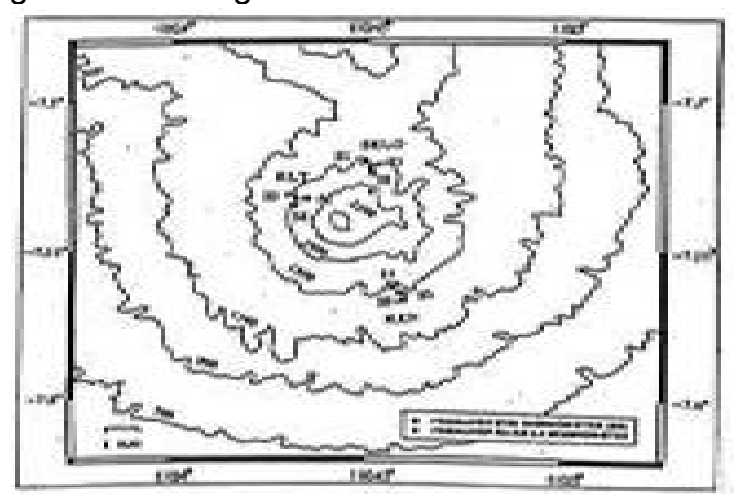

Gambar 4. Posisi Seismometer 


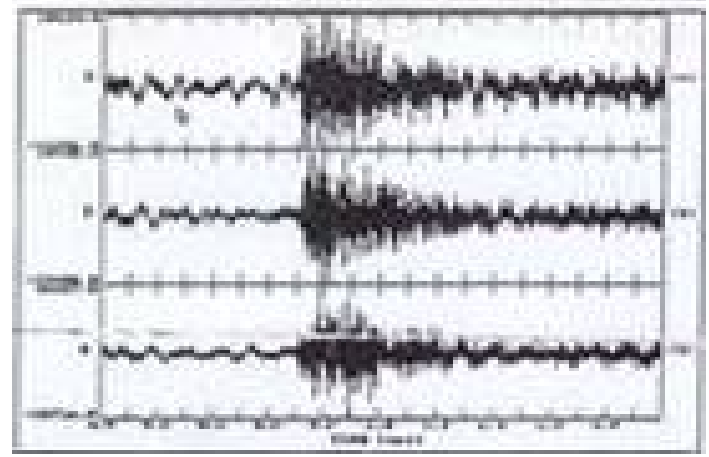

Gambar 5. Data Gempa Volkanik

Data dianalisis pada 2 kawasan, yaitu kawasan waktu, dan kawasan frekuensi. Analisis pada kawasan waktu diperoleh waktu tiba gempa volkanik, kawasan frekuensi diperoleh informasi tentang frekuensi sumber dan lebar pita frekuensi yang akan diloloskan, dan kawasan ruang ditentukan hiposenter gempa volkanik. Hasil analisis mendapatkan frekuensi sumber $6 \mathrm{~Hz}$ dan lebar pita frekuensi $0,1 \mathrm{~Hz}$. Hasil analisis pada kawasan waktu dan frekuensi dengan menggunakan program PITSA under LINUX dapat dilihat pada gambar 6.
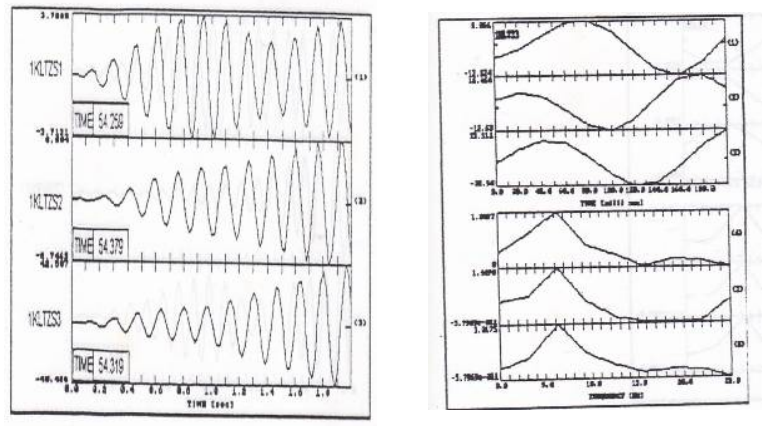

Gambar 6. Hasil Analisis pada Kawasan Waktu dan Frekuensi

Berdasarkan waktu tiba dan posisi seismometer dan analisis dengan HIPO9 didapatkan pengeplotan pada peta kontour dan kedalaman gunung Merapi sebagai berikut,

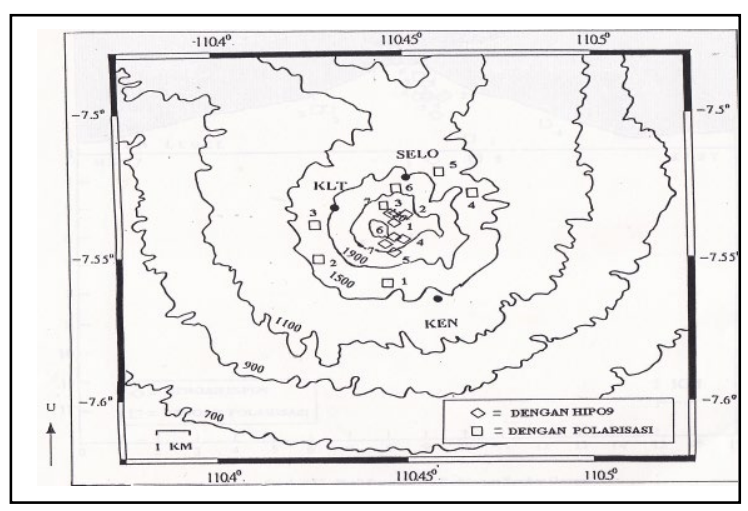

Gambar 7. Sebaran Episenter Gempa Volkanik

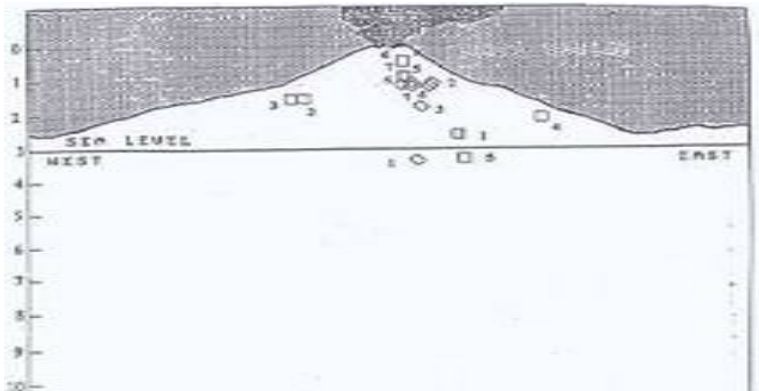

Gambar 8. Sebaran Posisi Hiposenter Gempa Volkanik

Sebaran gempa volkanik yang didapatkan sesuai dengan model internal gunung api dari hasil penelitian Fadeli (1987). Fadeli (1987) membuat model pipa dan kantong magma berdasarkan analisis tremor volkanik. Wahyudi (1986) juga menemukan model dapur magma gunung Merapi dengan menggunakan metode gravity.Ini diperkuat oleh penemuan Zarkoni, (1986) dengan metode magnetik. Gambar 9 adalah model struktur bawah permukaan gunung Merapi.

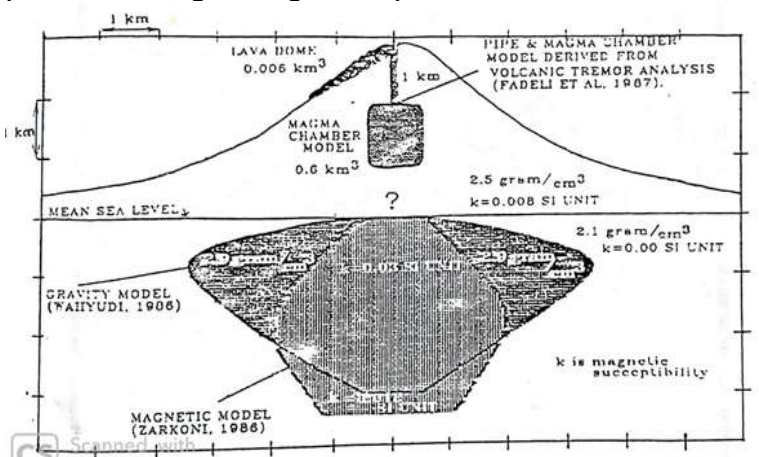

Gambar 9. Model Struktur Bawah Permukaan Gunung Merapi (Kirbani, 1988)

Bila dibandingkan sebaran episenter dan hiposenter gempa volkanik gunung Merapi dengan model struktur bawah permukaan gunung Merapi (Kirbani, 1998) terlihat jelas saling menguatkan. Jadi posisi episenter dan hiposenter gunung Merapi dapat juga mengungkapkan kondisi internal suatu gunung Merapi.

\section{SIMPULAN}

Berdasarkan hasil pengeplotan didapatkan kesimpulan posisi episenter dan kedalaman sumber gempa volkanik dengan HIPO9 cenderung mengumpul di sekitar puncak gunung merapi, dengan hiposenter gempa volkanik terdistribusi pada kedalaman $1200 \mathrm{~m}$ sampai $1300 \mathrm{~m}$.

\section{UCAPAN TERIMA KASIH}

Penelitian ini terselenggara dari bantuan banyak pihak, terutama laboratorium geofisika FMIPA Universitas Gadjah Mada Yogyakarta. Terima kasih yang sebesar besarnya juga 
kami sampaikan kepada bapak (alm) Prof.Dr. Kirbani Sri Brotopuspito dan bapak Dr. Budi Eka Nurcahya, M.Si.

\section{DAFTAR RUJUKAN}

Bruestle, W. (1985). Analog and Digital Signal Processing. Yogyakarta: FMIPA Universitas Gadjah Mada.

Civetta, L. (1974). Physical Volcanology. Tokyo: Developments in Solid Earth Geophysic Takeshi Minakami.

Fadeli. (1987). Pipe and Magma Chamber Model Derived from Volcanic Tremor Analysis. FMIPA Universitas Gadjah Mada: Laporan Penelitian.

Kirbani, S.B. (1990). Analysis of Volcanic Tremor at Mt. Merapi (Central Java Indonesia) in Order to Understanding Internal Magma Flow. Doctoral Thesis, Physic Dept. Gadjah Mada University. Indonesia.

Kirbani, S.B. (1996). Penggunaan Seismometer BroadBand dalam Pengukuran Seismisitas Gunung Krakatau, Laporan Penelitian. FMIPA UGM, Indonesia.

Kirbani, S. B., Budi, E.N., Wahyudi, I., Susanto, A. Setiawan. (1993). Analisis Polarisasi Data Seismik Gunung Merapi, Krakatau, Semeru. Yogyakarta: Laporan Penelitian Basic Science.

Kirbani, S.B., A.Fadeli, R.Mugiono. (1998). Review of Development of a Geophysical Volcano Research Laboratory to Investigate the Merapi Volcano in Central Java, Indonesia. Paper Presented at the Project-Site Seminar on Sabo Works, Sub-Theme IV (Warning System), Volcanic Sabo Technical Center October 11-13, Yogyakarta.

Rahardja. N. (1984). Laporan Analisa Gempa Gunung Merapi dengan Program Hyposeis dan Hypoplot. Jakarta: Proyek Penyelidikan dan Pengamatan Gunungapi Direktorat Vulkanologi.

Scherbaum, F. (1991). Programmable Interactive Toolbox for Seismological Analysis. Germany: Institut fur Allgemeine und Angewandte Geophysik der Ludwig Maximilians Universitat.

Setiawan, A. (1993). Pengukuran Seismik 3 Komponen dan Analisis Polarisasi Kegiatan Seismik Gunung Merapi pada Saat Pembentukan Kubah Lava tahun 1992. Thesis S-2 Pascasarjana UGM Yogyakarta.
Sukrisna. (1997). Penentuan Posisi Sumber Gempa Volkanik Data Seismogram Tiga Komponen Broad Band. Tesis S2, Fakultas Pascasarjana UGM Yogyakarta.

Syahrial, A. (2019). Model Pembelajaran Kesiapsiagaan Gempabumi di Sekolah Dasar. Jurnal Orbita Universitas Muhammadyah Mataram, 5(2), 65-72.

Wahyudi. (1991). Studi tentang Karakteristik Sumber Gempa Volkanik di Gunung Merapi Jawa Tengah. Thesis S-2, Fakultas Pascasarjana UGM, Yogyakarta.

Wakidi. (1996). Analisis Koherensi Gelombang Seismik Gempa Volkanik Gunung Anak Krakatau 6 Mei 1993. Skripsi S-1 Program Studi Geofisika UGM.Yogyakarta. 